\title{
HEMS technique for heat-harm control and geo-thermal utilization in deep mines
}

\author{
Pingye Guo $\cdot$ Guolong Zhu $\cdot$ Manchao He
}

Received: 25 March 2014/Revised: 13 May 2014/ Accepted: 13 May 2014/Published online: 31 October 2014

(C) The Author(s) 2014. This article is published with open access at Springerlink.com

\begin{abstract}
With the increasing exploitation scope and intensity, the shallow resources would be exhausted in the future; and the deep mining will become an essential choice. In deep tunnel engineering, the heat-harm becomes one of the main barriers. Investigations on high temperature coal mine have been done in Northern China, with the constructing of three models of high temperature mines suffering heat-harm, at the Jiahe mine, Sanhejian mine and Zhangshuanglou mine. The domestic and abroad cooling technologies of the mine respectively are also summarized after comparatively analyzing the advantages and disadvantages of each technology. Finally, we find that the high temperature exchange machinery system (HEMS) technology that use mine discharge as the cold source, is excellent to heat-harm control in deep mines. Taking the Jiahe coal mine as an example, we systematically introduce this technology by disposing three main workstations. HEMS technology with its operations and functions in different exploitation levels are accomplished, including the extraction of refrigerating output, the transportation of chilled water by closed circulation line, the decompression of circulation lines and equipment by pressure transformation machine, and the heat exchange and cooling of workplace by heat exchange between wind stream and the chilled water. The exchanged heat source from the workplace is taken to ground heating by the circulating water which acts as a carrier. It shows that the HEMS-technology benefit in environment protection and emission reduction. Results of this project illustrate that it is efficient in heat-harm control with the temperature decrease of the workplace down to $26-29{ }^{\circ} \mathrm{C}$, and being $4-6{ }^{\circ} \mathrm{C}$ lower than the original, and the relative humidity $5 \%-15 \%$ lower than before. It greatly improves the working environment of underground workplace suffering heat-harm of high temperature and high humidity. In addition, by the extracting of deep geothermal energy, ground fired boiler for heating has been replaced, reducing environmental pollution. This technology is worth generalization in deep mines and related fields.
\end{abstract}

Keywords Deep mine $\cdot$ High temperature $\cdot$ Heat-harm control $\cdot$ Mine discharge $\cdot$ Deep geothermal energy $\cdot$ High temperature exchange machinery system (HEMS)

\section{Introduction}

Geo-thermal energy is a great amount of thermal energy, but it could turn to be heat-harm if not being explored and utilized. As most mines in eastern China were explored deeper, with the increasing of exploration depth, the rock temperature rises, and high temperature heat-harm during

P. Guo $(\bowtie) \cdot$ G. Zhu $\cdot$ M. He

State Key Laboratory of Geomechanics and Deep Underground Engineering, Beijing 100083, China

e-mail: guopingye@foxmail.com exploration and at working face would become more and more serious (He et al. 2005). High temperature heat-harm would not only greatly harm the physical and mental health of mine workers, but also lead to safety accidents, and parts of absorbed gas could be released by environmental temperature increasing causing great potential safety problems. So it is extremely urgent to control high temperature heatharm (Deng 1992; Feng and Ceng 2005; He et al. 2008).

This paper, through the survey and analysis on deep mines in Eastern China, summarizes features of three typical heat-harm mines. On the basis of summarizing and analyzing previous heat-harm control technologies, and 
aiming at the usage of deep geo-thermal energy, HEMStechnology has been successfully developed. With the utilization of deep mine heat-harm as resources, ground coal-fired boiler has been replaced to achieve the mining area's purpose of saving energy, protecting environment and sustainable developing, while solving deep mine heatharm problems.

\section{Distribution patterns of geothermal field}

Ground temperature of geothermal field in deep mines gradually increases with the mining depth. There are important factors in different geological environments still exist, such as the impact of the regional geological structure, the groundwater and mine inflows, etc. These factors form the various geothermal gradients and distribution patterns in deep mines. According to temperature gradients in China's deep mines, the patterns can be generalized as three kinds, linear, nonlinear and abnormal pattern, of typical deep geothermal field distribution patterns.

\subsection{Linear}

According to the data of ground temperature measurement in China's mainland, the temperature of shallow ground regularly present in linear variation pattern, showing general linear temperature distribution on a diagram temperature $(T)$ versus depth $(Z)$. Figure 1 presents the result of geothermal distribution in one of the scientific drilling holes in China.

As is shown in Fig. 1: (1) The measuring temperature under $100 \mathrm{~m}$ is uniformity; (2) at $900-1,600 \mathrm{~m}$ section, temperature shows fluctuations, slightly influenced by groundwater activity; (3) in the deep underground area, linear relation between temperature and depth is conspicuous; (4) The value of the geothermal gradient is changeable, decreasing or increasing with the variation of depth. The average geothermal gradient is about $24.18 \pm 3.14{ }^{\circ} \mathrm{C} / \mathrm{km}$.

Most part of the ground temperature field in China distributes in this type, and when the mine mining depth is less than $800 \mathrm{~m}$, generally serious thermal pollution won't appear. Some of individual mines suffer from the overheat damage, usually not serious, which could be easily and effectively solved by improving the ventilation system, adjusting proper ventilation rate, instead of using artificial refrigeration cooling technology. But when it comes to under $800 \mathrm{~m}$ and even deeper, the temperature is more than $40^{\circ} \mathrm{C}$, causing serious thermal pollution, in which artificial refrigeration cooling technologies must be taken in.

\subsection{Nonlinear}

Due to the impact of regional tectonic and other influence factors, some of the mines perform a significant

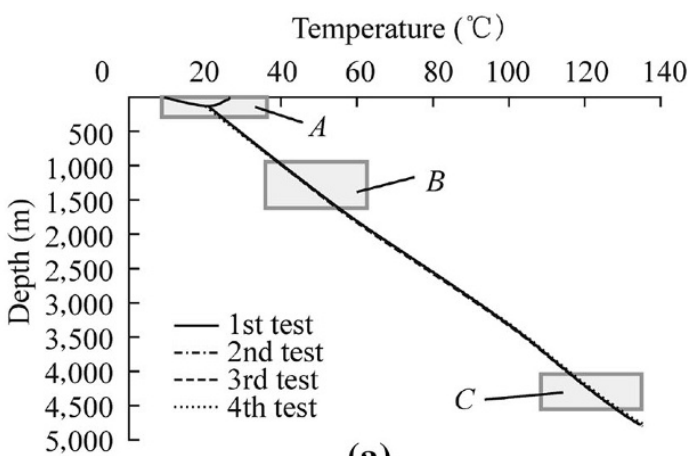

(a)

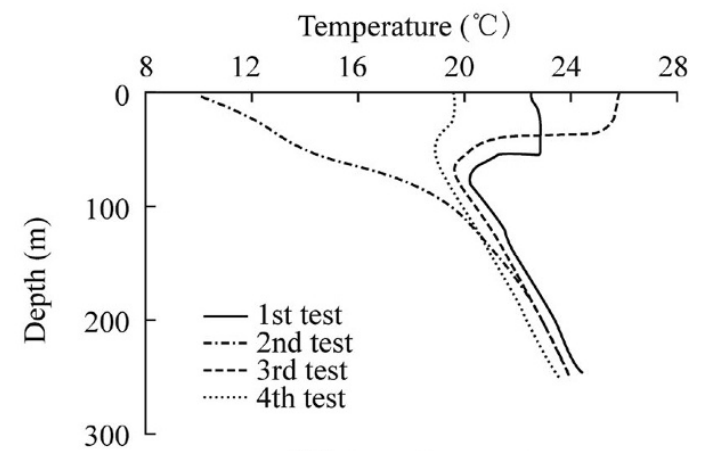

(b) Zoom in area $A$

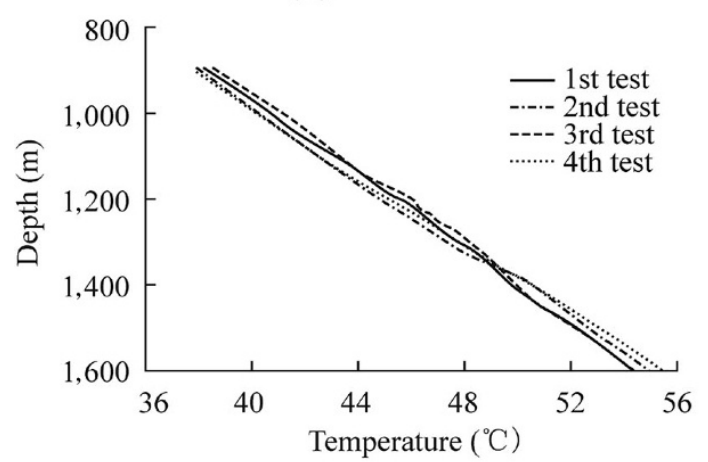

(c) Zoom in area $B$

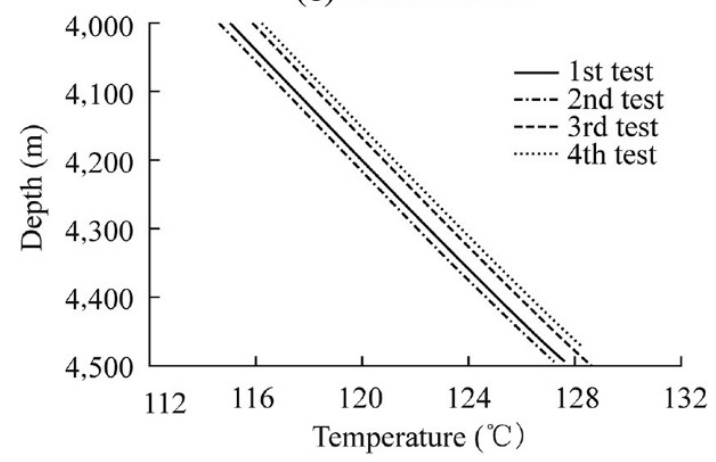

(d) Zoom in area $C$

Fig. 1 Distribution of temperature with depth

nonlinearity in the distribution of geothermal gradient as the depth increases. Jiahe coal mine (Xuzhou Mining Group, Jiangsu Province) is one of these cases. The data of ground temperature in Jiahe mine are shown in Fig. 2. 


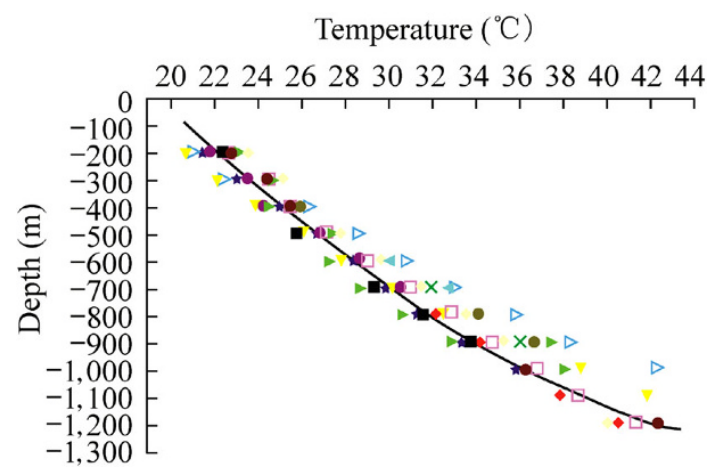

Fig. 2 Nonlinear distribution of ground temperature

From Fig. 2 it can be concluded as the following,

(1) The function of ground temperature with depth varies with a formula:

$T(h)=-4.975+23.08 \exp (-h / 1736.1) ;$

(2) From 200 to $700 \mathrm{~m}$, a basic linear geothermal gradient is achieved equal to $1.5^{\circ} \mathrm{C} / 100 \mathrm{~m}$;

(3) From 700 to $1,200 \mathrm{~m}$ depth, a non-linear variation is achieved with the average geothermal gradient of $2.2{ }^{\circ} \mathrm{C} / 100 \mathrm{~m}$.

When the mining depth reaches 700 to $1,200 \mathrm{~m}$, the temperature increases with the mining depth, and keeps increasing with a non-linearly trend. According to the statistics of China's thermal disasters in coal mines, when the mining depth is larger than 1,000 m, severe heat damage phenomena would be suffered, and the nonlinear distribution of geothermal heat will exacerbate the degree of heat disaster in mines.

\subsection{Abnormal pattern}

Because of the differences in geological structure and stratigraphic distribution factors, if there is a local hot rock formation, it will cause abnormal changes in geothermal temperature, such as the ground temperature distribution of Sanhejian mine (Xuzhou Mining Group, Jiangsu Province), and the distribution is shown in Fig. 3. Rich Ordovician limestone water exists in Sanhejian coal mine, and the temperature of water is about $50{ }^{\circ} \mathrm{C}$, with the quantity up to $1,000 \mathrm{~m}^{3} / \mathrm{h}$. The large amount of high-temperature water causes a severe heat damage to Sanhejian mine all a year round. Besides, the Juye coal mine and Longgu mine in Shandong Province also belong to this pattern of geothermal distribution. As is shown in Fig. 3, the temperature increases with the increase of depth at first stage, but a sudden change of temperature appears at local depth, forming the anomaly geothermal distribution.

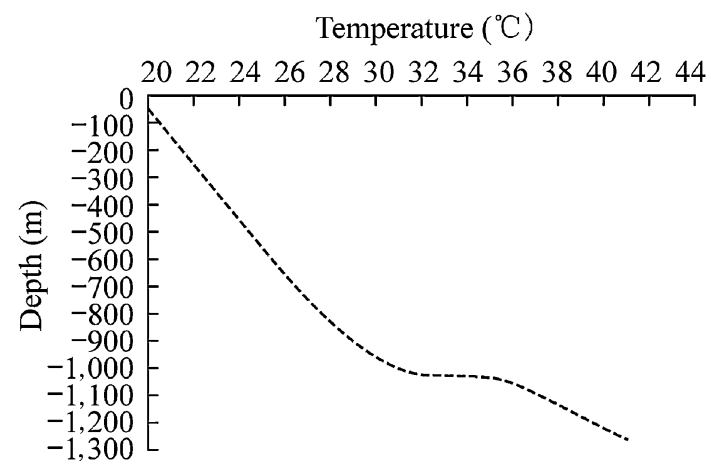

Fig. 3 Abnormal pattern of geothermal distribution

Table 1 Typical high temperature mines list in North China

\begin{tabular}{lllll}
\hline $\begin{array}{l}\text { Temperature on } \\
\text { working face }\left({ }^{\circ} \mathrm{C}\right)\end{array}$ & $\begin{array}{l}\text { Shandong } \\
\text { province }\end{array}$ & $\begin{array}{l}\text { Jiangsu } \\
\text { province }\end{array}$ & $\begin{array}{l}\text { Anhui } \\
\text { province }\end{array}$ & $\begin{array}{l}\text { Henan } \\
\text { province }\end{array}$ \\
\hline$>26$ & 13 & 5 & 10 & 12 \\
$26-30$ & 6 & 3 & 7 & 2 \\
$>30$ & 7 & 2 & 3 & 10 \\
\hline
\end{tabular}

\section{Three typical heat-harm modes}

According to the data surveyed by China University of Mining and Technology (Beijing) and China Coal Mine Safety Supervision Bureau for mining areas in eastern China, there are 13 mines in Shandong whose temperature on working faces is higher than $26^{\circ} \mathrm{C}$, among which six mines' temperature on working face is between 26 and $30{ }^{\circ} \mathrm{C}$, seven of them is higher than $30^{\circ} \mathrm{C}$; in Jiangsu Province there are five mines in all with the temperature on working face higher than $26^{\circ} \mathrm{C}$, among which three mines' temperature on working face is between 26 and $30{ }^{\circ} \mathrm{C}$, two is higher than $30{ }^{\circ} \mathrm{C}$; in Anhui Province there are 10 mines in all that temperature on working face is higher than $26{ }^{\circ} \mathrm{C}$, among which seven of them the temperature on working face is between 26 and $30^{\circ} \mathrm{C}$, and three mines are higher than $30^{\circ} \mathrm{C}$; there are 12 mines in all in Henan Province whose temperature on working face is higher than $26{ }^{\circ} \mathrm{C}$, among which two mines' temperature on working face is between 26 and $30{ }^{\circ} \mathrm{C}$, and 10 mines' temperature is higher than $30{ }^{\circ} \mathrm{C}$ (Table 1$)$.

On another hand, ground heating in mining area is usually supplied by coal-fired boiler, with low efficiency and high wasting of one-time energy, and coal-firing emits large amount of $\mathrm{CO}_{2}$ and $\mathrm{SO}_{2}$, increasing global warming and environmental pollutions. Boiler emission of some typical mining area is in Table 2 .

On the basis of this survey, according to hydro geological conditions and heat-harm of various mines, three 
Table 2 Coal-firing boiler emission of typical mining area (t)

\begin{tabular}{llll}
\hline Coal mines & Coal consumption & $\mathrm{CO}_{2}$ emission & $\mathrm{SO}_{2}$ emission \\
\hline Jiahe & 12,500 & 19,000 & 130 \\
Sanhejian & 12,045 & 18,600 & 130 \\
Zhangshuanglou & 11,970 & 17,000 & 98.3 \\
\hline
\end{tabular}

typical mining modes of heat-harm are summarized: Jiahe mode, Sanhejian mode and Zhangshuanglou mode.

\subsection{Jiahe mode (Zhang 2006)}

This type of heat-harm mines locate at the area with normal ground temperature, and the heat-harm mainly comes from the rise of rock temperature with exploration depth increasing. Representative mines of this type are deep mines with more than 1,000 m depth such as Xuzhou Jiahe coal mine, Huainan Jiulonggang coal mine, Xinwen Sun village coal mine, etc. Mainly features are as the following:

(1) Gradient of ground temperature in this type of mines with heat-harm is less or near to the average, without heat-harm when explored at superficial part, but heat-harm appears as the ground temperature rising while the exploration depth increasing. It could be obvious at $-800 \mathrm{~m}$ level of Jiahe mine where the rock temperature is $33-34{ }^{\circ} \mathrm{C},-1,000 \mathrm{~m}$ level around $38-39^{\circ} \mathrm{C}$, and the temperature on heading face is as high as $35-36{ }^{\circ} \mathrm{C}$.

(2) Lack in undermine water resource, for example, the amount of mine water in Jiahe mine is $95-135 \mathrm{~m}^{3} / \mathrm{h}$.

(3) Coal-firing boiler was used on the ground of heating and bathing, with large consumption of resources and serious pollution.

\subsection{Sanhejian mode (He et al. 2010)}

Due to anomaly geothermal underground environment and the heat of hot water, high temperature heat-harm in this kind of mines is serious. Representative mines include Xuzhou Sanhejian coal mine, Pingdingshan No. 8 coal mine, Chenzhou uranium mine, etc. with main features:

(1) Gradient of ground temperature of this kind is larger than the average, which commonly possesses complete crustal thermal structure and poly thermal structure. For example, the gradient of ground temperature in Sanhejian coal mine is $3.46{ }^{\circ} \mathrm{C} /$ $100 \mathrm{~m}$, larger than the average value, with good poly thermal structure and crustal thermal structure. It could be seen in Diagram 2 that the rock temperature at $700 \mathrm{~m}$ level in Sanhejian mine is $37.7^{\circ} \mathrm{C}$, at 860 level is $43.9{ }^{\circ} \mathrm{C}$, and at $980 \mathrm{~m} 46.8^{\circ} \mathrm{C}$. Temperature on heading face is high of about $36-37^{\circ} \mathrm{C}$, which can affect physical and mental health of the workers, as well as production safety can be seriously threatened.

(2) Be scarce in underground cold water as cold source, but rich in hot water with high temperature, containing large amount of geothermal resource. For example, the flow of water in Sanhejian mine is only $50 \mathrm{~m}^{3} / \mathrm{h}$ with temperature around $25-30{ }^{\circ} \mathrm{C}$, but $1,020 \mathrm{~m}^{3} / \mathrm{h}$ water flow which is $50{ }^{\circ} \mathrm{C}$. Underground hot water is aggravated by the heat-harm.

(3) Coal-firing boiler was used on the ground for heating and bathing, which can be substituted by hot water existing inside the mine.

\subsection{Zhangshuanglou mode}

Gradient of ground temperature in this kind of mines is normal, and heat-harm commonly exists at deep part, but this kind is rich in mine water, containing plenty of lowgrade cold energy. Representative mines are Xuzhou Zhangshuanglou coal mine, following the features as:

(1) No heat-harm at superficial part of this kind of mines, but with the exploration depth increasing, heat-harm becomes more and more serious. For example, temperature on working face in Zhangshuanglou is higher than $36{ }^{\circ} \mathrm{C}$,

(2) Rich in mine water, for example, flow of mine water is $1,200 \mathrm{~m}^{3} / \mathrm{h}$ in Zhangshuanglou mine,

(3) As referred before coal-firing boiler used on the ground for heating and bathing, can be substituted by hot water existing inside the mine.

\section{Heat-harm control system existing in China and in foreign countries}

\subsection{Central air conditioning system}

This system cools return water by spray facilities, sometimes adding auxiliary fans in cooling system, or using heat-exchanger between wind and water to enhance cooling effect. Cold water of the unit finishes heat-exchanging with intake air flow passing air cooler, and the cooled air flows is conveyed by fans to working face through wind tunnel for working face cooling. According to the layout, central air conditioning system gradually developed in two modes, the ground centralized and underground centralized mode, and the principle diagram of this technology is shown in Fig. 4. Large depth, high pressure and high cost 


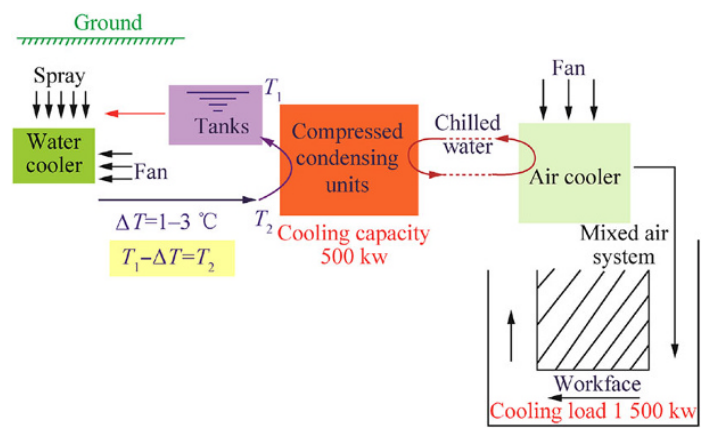

Fig. 4 Principle diagram of central air conditioning cooling

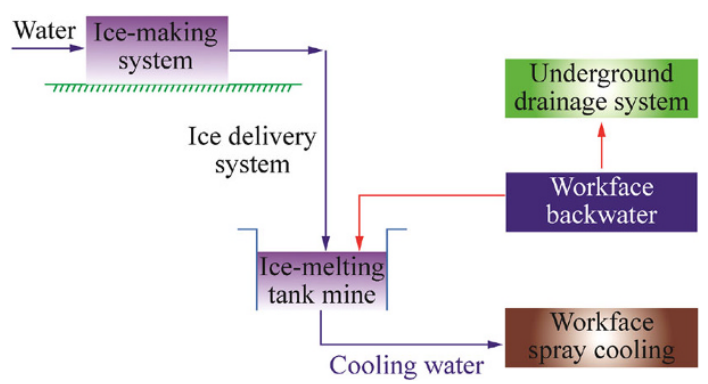

Fig. 5 Cooling principle diagram of ice cooling system

cause the main troubles in this system; for underground centralized mode, the problems in heat elimination, weak cooling effect (because of the limited circulating water temperature difference, and mixed air system) and high operation cost are obvious (He et al. 2004).

\subsection{Ice cooling system}

The ice cooling system, using granular ice or mashed ice manufactured by ice maker and conveying to ice-melting pool underground, uses return water from working face spraying to melt the ice, then conveys the cold water to working face and sprays the water for cooling. The system is mainly comprised with three parts, the ice production station, ice conveyance and ice melting part. Figure 5 is the technology principle diagram of ice cooling system. But this system also have disadvantages: ice pipelines are easy to be blocked leading to whole system down, and the spray cooling would increase humidity, thirdly, the operation cost is high.

\subsection{Thermoelectric glycol system}

Thermoelectric glycol technology, firstly transmits residual heat from gas power plant to lithium-bromide refrigerating machine for first-stage cooling and then transmits to glycol refrigerating machine for second-stage cooling with the temperature of $-3.4{ }^{\circ} \mathrm{C}$ to $-5{ }^{\circ} \mathrm{C}$. The cooled glycol is

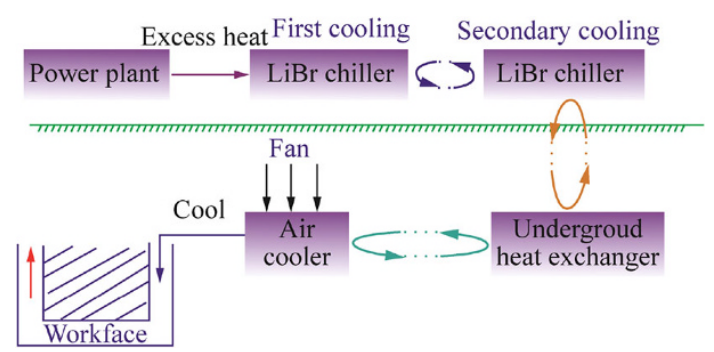

Fig. 6 Cooling principle diagram of thermoelectric glycol system

conveyed to underground workstation for water cooling, and the cooled water is conveyed to air cooler for air cooling. Cold air is then transmitted to high temperature working face for cooling. By using this system, the temperature on heading face reduces from 34 to $26^{\circ} \mathrm{C}$. The temperature of cold glycol solution is $-5{ }^{\circ} \mathrm{C}$, and only $3{ }^{\circ} \mathrm{C}$ when reaching heat-exchange system, averagely reducing the temperature of underground working face by $10{ }^{\circ} \mathrm{C}$. Figure 6 is the technology principle diagram of this system. The cooling effect of this system is obvious, but it requires that the mine must have a power plant; secondstage cooling of cold resources make the cold quantity limited; the operation is complex, and the cost is high. All these make it difficult to spread for heat-harm controlling in deep mines.

\section{High temperature exchange machinery system (HEMS)}

There's a common problem in all the three cooling systems above, that they are all energy consumption systems with a single goal for cooling, consuming plenty of energy in operation, not regarding the heat-harm in deep mines as a kind of resource, and large amount of deep geo-thermal energy has been wasted. Aiming at making use of the heatharm, HEMS is developed by the State Key Laboratory of Geomechanics and Deep Underground Engineering, China University of Mining and Technology (Beijing), relying on a 973 China National project (2006CB202200) (He et al. 2006a, b; He and Qu 2007). The system combines cooling, using underground mine water drainage, and utilization of heat-harm as geo-thermal energy, achieves the purpose of underground heat-harm control and the ground coal-firing boiler heating replacement, forming a green circular production system with cooling underground and heating on the ground (He et al. 2006b).

\subsection{System instruction}

Mine water is used in HEMS system as the medium to extract deep geo-thermal energy instead of coal-firing 


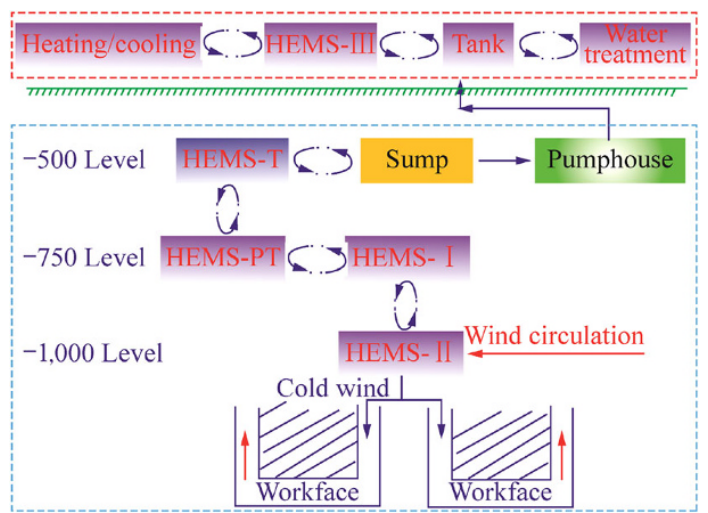

Fig. 7 Mine water cooling technology and its principle diagram

boiler heating on the ground, achieving the purpose of controlling underground heat-harm (Feng and Ceng 2005). Figure 7 shows the technology principle diagram of HEMS. The system comprises two parts, the underground and the ground part. The workstation underground includes HEMS-II cooling station, HEMS-I cooling station, HEMSPT pressure conversion station, HEMS-T heat exchange station and the pumping station; the ground part includes regulating pond, HEMS-III heating station and water treatment system (Zhang 2006). Functions of each station and detailed process are described as the following:

(1) HEMS-II-cooling station conveys cold energy by water-gas heat exchange for working face cooling to control heat-harm, and at the same time conveying thermal energy to HEMS-I cooling station.

(2) HEMS-I-cooling station, when conveying cold energy to HEMS-II cooling station, conveys the produced thermal energy to HEMS-PT pressure conversion station.

(3) HEMS-PT-pressure conversion station solves the problem of high liquid pressure on pipes, at the same time conveying thermal energy produced in HEMS-I cooling station to HEMS-T heat exchange station.

(4) HEMS-T-heat exchange station is designed for high physical abrasion, high mineralization, and strong chemical corrosion liquid, and successfully delivers thermal energy to mine water by energy exchanging.

(5) Finally convey deep geo-thermal energy to the regulated pond on the ground by drainage system, and convert low-grade thermal energy to high-grade thermal energy by HEMS-III heating station on the ground for heating, the mine water whose thermal energy is extracted is recycled after passing water treatment system, achieving drainage standards.

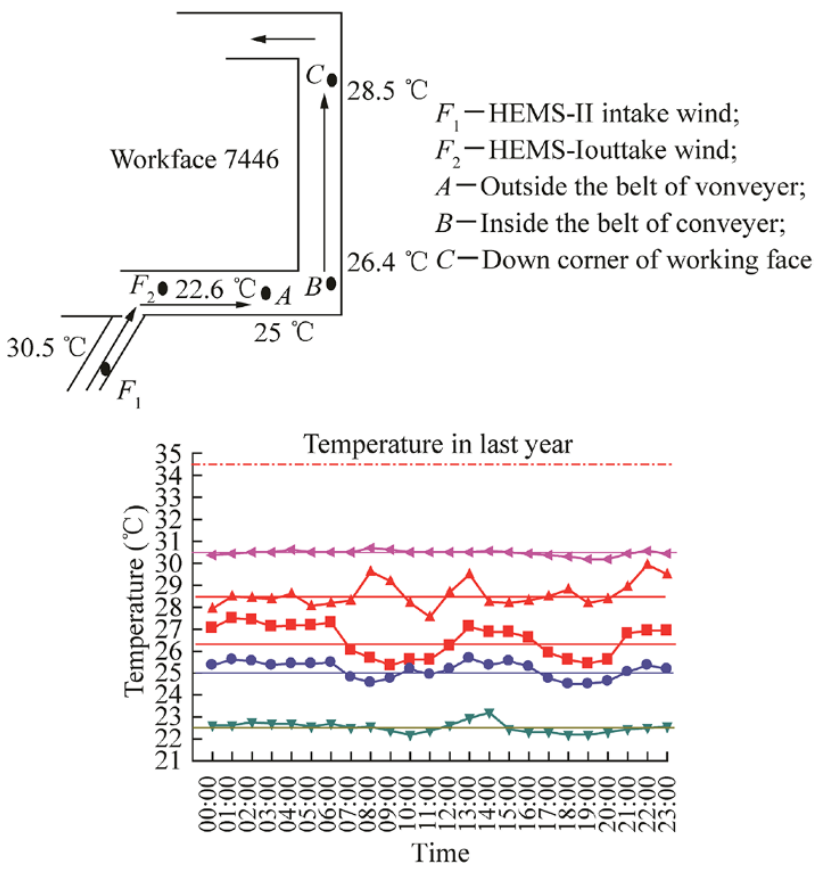

Fig. 8 Cooling effect on working face 7446

\subsection{Effect analysis}

HEMS system is successfully applied in Xuzhou coal mines such as Jiahe, Sanhejian and Zhangshuanglou coal mine, the results shows that the underground cooling is obvious and efficient, while the heating on the ground is steady and reliable. Detailed data are shown in the following sub-sections.

\subsubsection{Underground cooling effect}

In the operation process, there are a great deal of features and data during the system operating each day. As is shown (Figs. 8, 9), the temperature of intake wind at working face is $30.5^{\circ} \mathrm{C}$, and decreasing to $22.6{ }^{\circ} \mathrm{C}$ when passing the cooling machine, reaching the working face around $26.4^{\circ} \mathrm{C}$. The temperature at corner point $C$ of working face is controlled to reduce by $6{ }^{\circ} \mathrm{C}$ than that in the same period of $2006,34.5^{\circ} \mathrm{C}$, meeting the production requirements. By the data analysis of the whole cooling season, temperature decreasing scope is $4-6{ }^{\circ} \mathrm{C}$, and the system reduces not only the temperature, but also the humidity by $5 \%-10 \%$.

The overall running effect shows that the temperature controlled on working face is steady, around $26-29^{\circ} \mathrm{C}$, compared with the average temperature on working face before operating the system, which decreases by $4-6{ }^{\circ} \mathrm{C}$ after operating our system; relative humidity of intake wind decreases most after passing HEMS-II cooling device, relative humidity of roadway wind continuously rises when 


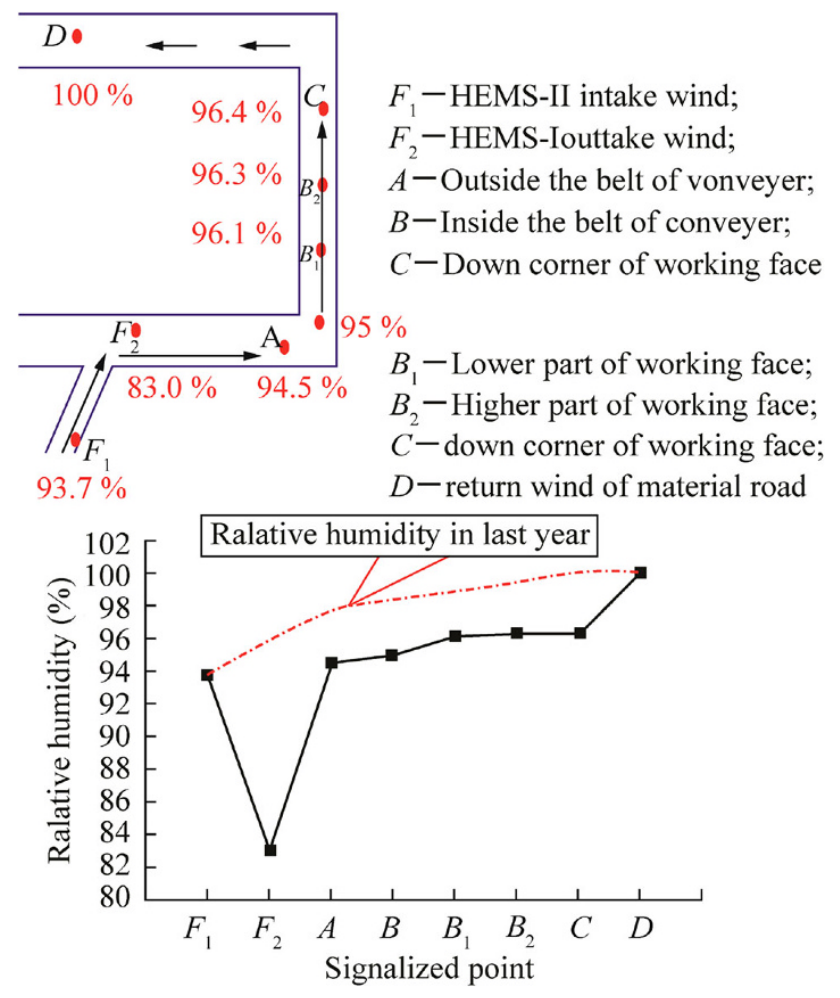

Fig. 9 Analysis of relative humidity variation on working face 7446

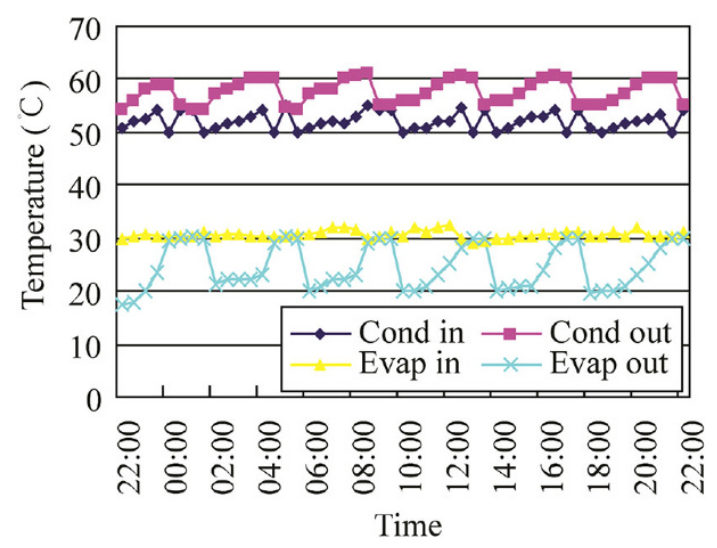

Fig. 10 Ground heating running data

conveyed to working face, the relative humidity at controlling point $C$ is $96.4 \%$, and that at air intake vent is $83 \%$. Relative humidity on working face before operating the system is $100 \%$, so after operating the system the relative humidity decreases by $3.6 \%-17 \%$, largely improving the working environment for workers.

\subsubsection{Ground heating effect}

The designation of water temperature for heating is $60{ }^{\circ} \mathrm{C}$, and the return water is $50^{\circ} \mathrm{C}$. Figure 10 shows the running data of HEMS-III heating unit for $24 \mathrm{~h}$, fully meeting the heating requirements. The temperature of water supplied for the unit is fluctuating around $60{ }^{\circ} \mathrm{C}$, because of the automatic control of supplied and returned water temperature; when the temperature of unit reaches the designed $60{ }^{\circ} \mathrm{C}$, the unit would restart to meet heating requirements.

\section{Conclusions}

This paper, aiming at deep mine heat-harm control and utilization of thermal heat, introduced the development and field test of HEMS, getting conclusions as following:

(1) By the analysis of current situation of mines in eastern China, summarize the main problems faced in deep mines, the heat-harm control, energy waste and environmental pollution problems by ground coal-firing boiler.

(2) Three modes of mines with heat-harm are introduced, Jiahe mode, Sanhejian mode and Zhangshuanglou mode, according to plenty of analysis of background information about temperature variation and hydro conditions in mines with heat-harm.

(3) HEMS has been successfully developed and put into field tests, with the medium of mine water, thermal energy capture is achieved by exchanging while controlling the heat-harm on working face, and the ground coal-firing boiler can be replaced.

(4) Field application has been taken at Jiahe, Sanhejian, Zhangshuanglou coal mines of Xuzhou Mining Group. After the system operating, the temperature at underground working face could be controlled around $26-30{ }^{\circ} \mathrm{C}$, decreasing $5-7{ }^{\circ} \mathrm{C}$, and the relative humidity decreasing $5 \%-15 \%$, largely improving the working environment at working face. At the meanwhile, the ground coal-firing boiler were replaced by deep geo-thermal energy, saving $10,000 \mathrm{t}$ coal, $\mathrm{CO}_{2}$ emission was decreased for $17,000 \mathrm{t}, \mathrm{SO}_{2}$ for about $100 \mathrm{t}$, with great significance in energy saving and environmental protection.

Acknowledgments The financial support by the Key Program of National Natural Science Foundation of China (51134005) and Doctoral Scientific Fund Project of the Ministry of Education of China (20120023120004) is gratefully acknowledged.

Open Access This article is distributed under the terms of the Creative Commons Attribution License which permits any use, distribution, and reproduction in any medium, provided the original author(s) and the source are credited. 


\section{References}

Deng X (1992) Review and prospect of study in mining geothermics. Adv Earth Sci 7(3):20-24

Feng XH, Ceng RH (2005) Research and development on air-cooling in deep high-temperature mines at home and abroad. Yunnan Metall 34(5):7-10

$\mathrm{He}$ MC, Qu XH (2007) Engineering principle and its application of stratum new energy. J Archit Civ Eng 24(4):91-94

He MC, Li CH, Zhu JL, Xu NX, Zhang BX, Yao LH et al (2004) China geothermal engineering technology of middle and low enthalpy. China Science Press, Beijing

He MC, Xie HP, Peng SP, Jiang YD (2005) Study on rock mechanics in deep mining engineering. Chin J Rock Mech Eng 24(16): 2803-2813

He MC, Zhang Y, Guo DM (2006a) Storage cold energy system in deep mine heat hazard of new energy administration. China Min Mag 15(9):62-64
He MC, Zhang Yi, LI QM (2006b) Geothermal energy engineering application in insteading of alkene in hospital. China Min Mag Min Res Dev 26(4):44-46

He LJ, Hu SB, Huang SP, Yang WC, Yuan YS, Yang SC (2008) Heat flow study at the Chinese continental scientific drilling site: borehole temperature, thermal conductivity and radiogenic heat production. J Geophys Res 113:B024404

He MC, Guo PY, Chen XQ, Meng L, Zhu YY (2010) Research on characters of high-temperature and control of heat-harm of Sanhejian coal mine. Chin J Rock Mecha Eng 29(Supp. 1):2593-2597

Zhang Y (2006) Mechanism of deep heat damage and its control measures in Jiahe coal mine. China University of Mining \& Technology, Beijing 